\title{
SARCOMA DE KAPOSI ANAPLÁSICO MIMETIZANDO ANGIOSSARCOMA
}

\author{
Vera Teixeira', José Carlos Cardoso², Miguel Pinto Gouveia', Angelina Mariano², Óscar Tellechea ${ }^{3 *}$, Américo \\ Figueiredo ${ }^{4 *}$ \\ IInterna(o) do Internato Complementar de Dermatologia e Venereologia/Resident, Dermatology and Venereology \\ ${ }^{2}$ Assistente Hospitalar de Dermatologia e Venereologia/Consultant, Dermatology and Venereology \\ ${ }^{3}$ Chefe de Serviço e Professor de Dermatologia e Venereologia/ Consultant Chief and Professor, Dermatology and \\ Venereology \\ ${ }^{4}$ Professor Doutor e Director do Serviço de Dermatologia e Venereologia do Centro Hospitalar e Universitário de \\ Coimbra/Professor of Dermatology and Venereology and Head of the Dermatology Department \\ *Faculdade de Medicina da Universidade de Coimbra \\ Serviço de Dermatologia e Venereologia, Centro Hospitalar e Universitário de Coimbra, Coimbra, Portugal
}

RESUMO - Introdução: O angiossarcoma é o tumor vascular mais frequente no contexto de linfedema crónico, entidade conhecida como síndrome de Stewart-Treves. Contudo, é sabido que o sarcoma de Kaposi se acompanha frequentemente de linfedema (por vezes antecedendo o aparecimento das lesões típicas), e que ocasionalmente a distinção entre sarcoma de Kaposi e angiossarcoma pode constituir um desafio diagnóstico. Caso clínico: Apresentamos o caso de um doente do sexo masculino, 69 anos de idade, com lesão em placa eritemato-violácea no membro superior esquerdo, sobre linfedema crónico. O estudo histológico mostrou uma proliferação de células epitelioides na derme, associada a atipia citológica e presença de fendas vasculares evocadoras de angiossarcoma. Contudo a correlação clínico-patológica associada ao exame de biologia molecular (PCR) permitiram estabelecer o diagnóstico de sarcoma de Kaposi anaplásico. Comentários: O nosso caso sublinha a dificuldade em diferenciar esta variante de sarcoma de Kaposi do angiossarcoma e o espectro de sobreposição clínica e histológica entre estas duas entidades.

PALAVRAS-CHAVE - Angiossarcoma; Neoplasias da pele; Sarcoma de Kaposi.

\section{ANAPLASTIC KAPOSI SARCOMA MIMICKING ANGIOSARCOMA}

ABSTRACT - Introduction: Angiosarcoma is the most common vascular tumor in the context of chronic lymphedema, known as Stewart-Treves syndrome. However, it is known that Kaposi's sarcoma is often accompanied by lymphedema (often precedes the onset of typical lesions), and occasionally distinguishing between Kaposi's sarcoma and angiosarcoma may be a diagnostic challenge. Clinical case: We present the case of a male patient, 69 years-old, with an erythematous-violaceous plaque on the left arm associated with chronic lymphedema. Histologic examination showed a proliferation of epithelioid cells in the dermis, associated with cytologic atypia and presence of slit-like vascular spaces evocative of angiosarcoma. However, the clinicopathological correlation associated with molecular biology (PCR) allowed the diagnosis of anaplastic Kaposi's sarcoma. Comments: Our case highlights the difficulty in differentiating this variant of Kaposi's sarcoma from angiosarcoma and the spectrum of clinical and histologic overlap between these two entities.

KEY-WORDS - Hemangiosarcoma; Lymphangiosarcoma; Sarcoma, Kaposi; Skin neoplasms.

\footnotetext{
Conflitos de interesse: Os autores declaram não possuir conflitos de interesse.

No conflicts of interest.
} 


\title{
Caso Clínico
}

\begin{abstract}
Suporte financeiro: $O$ presente trabalho não foi suportado por nenhum subsídio ou bolsa.
No sponsorship or scholarship granted.

Direito à privacidade e consentimento escrito / Privacy policy and informed consent: Os autores declaram que pediram consentimento ao doente para usar as imagens no artigo. The authors declare that the patient gave written informed consent for the use of its photos in this article.
\end{abstract}

Recebido/Received - Junho/June 2013; Aceite/Accepted - Julho/July 2013

Por decisão dos autores, este artigo não foi redigido de acordo com os termos do novo Acordo Ortográfico.

\author{
Correspondencic \\ Dr. $\stackrel{\underline{a}}{ }$ Vera Teixeira \\ Serviço de Dermatologia e Venereologia \\ Centro Hospitalar de Coimbra \\ Praceta Mota Pinto \\ 3000-075 Coimbra, Portugal \\ Tel.: + 351239400400 \\ Fax: +351239400490 \\ E-mail: vera.teixeira.derm@gmail.com
}

\section{INTRODUÇÃO}

O sarcoma de Kaposi (SK), descrito pela primeira vez, em 1872, por Moritz Kaposi (dermatologista húngaro), é uma neoplasia de células endoteliais classificada pela World Health Organization como um tumor vascular de baixo-grau de malignidade'. Tradicionalmente é classificado em 4 formas clínicas:

(1) Clássica ou crónica (afecta sobretudo homens idosos, de origem mediterrânica);

(2) Endémica (africana);

(3) latrogénica (SK associado a transplante/medicação imunossupressora);

(4) Epidémica (SK associado a SIDA).

As áreas preferencialmente atingidas pelo SK são os membros inferiores, a face, o tronco, os genitais ou a mucosa orofaríngea. Os gânglios linfáticos e outros órgãos viscerais podem também estar envolvidos ${ }^{2}$. Os achados histológicos não variam significativamente consoante a forma clínica, mas consoante o estadio das lesões (em mancha, placa ou nodular). Actualmente é reconhecida a importância do HHV-8 na histogénese deste tumor ${ }^{1,2}$. Tipicamente, o SK não tem um comportamento agressivo e os doentes com a variante clássica podem sobreviver 10 a 15 anos ou mais ${ }^{2}$.

$O$ angiossarcoma é um tumor maligno agressivo com diferenciação endotelial. $O$ prognóstico é reservado, com agressividade local e metastização à distância, sem resposta favorável à quimioterapia ${ }^{3}$. Pode ocorrer nos seguintes contextos clínicos: (a) Cabeça e pescoço, em doentes idosos - é o tipo clínico mais frequente. As lesões iniciais são máculas, por vezes simulando clinicamente uma simples equimose, localizadas mais comummente na região central da face, frontal ou couro cabeludo. Posteriormente, as lesões podem evoluir para nódulos friáveis e hemorrágicos;

(b) Pós-irradiação - em doentes previamente tratados com radioterapia. Apesar da incidência deste subtipo ser muito baixa, pensa-se que tenha aumentado ligeiramente com as abordagens mais conservadoras da neoplasia da mama. Surge sob a forma de nódulos ou placas infiltrativas na área previamente irradiada. De forma semelhante aos outros subtipos, esta forma tem prognóstico reservado;

(c) Linfedema crónico - cerca de $90 \%$ de todos os casos de angiossarcoma associados a linfedema crónico surgem em doentes submetidas a mastectomia e linfadenectomia axilar (Síndrome Stewart-Treves). Este tipo de angiossarcoma apresenta-se como um nódulo ou placa endurecida violácea sobre edema duro não depressível. Nestes casos, a região interna do braço é o principal local atingido. Outras formas de linfedema crónico associadas e angiossarcoma são: linfedema congénito, filaríase, linfedema traumático ou idiopático. A duração do linfedema previamente ao angiossarcoma varia entre 4 a 27 anos. Os mecanismos de associação entre linfedema crónico e angiossarcoma permanecem por esclarecer. Algumas teorias incluem a indução de transformação neoplásica por 


\section{Caso Clínico}

carcinogéneos desconhecidos que se acumulam no fluido linfático ${ }^{4}$.

Os achados histológicos são semelhantes entre os 3 tipos de angiossarcoma. Nos tumores bem diferenciados observa-se uma proliferação infiltrativa constituída por vasos anastomosantes, revestidos por uma única camada de células endoteliais, com atipia ligeira a moderada, que dissecam os feixes de colagénio e se estendem frequentemente à hipoderme. Nos tumores menos diferenciados as células endoteliais apresentam pleomorfismo nuclear marcado, actividade mitótica e podem formar projecções papilares dispondo-se em múltiplas camadas. Nas lesões indiferenciadas, a actividade mitótica é marcada, a atipia é mais acentuada e não se observa diferenciação vascular evidente, mimetizando portanto outros sarcomas de alto-grau, carcinomas ou melanoma. Nestes casos, a imunohistoquímica é determinante no estabelecimento de um diagnóstico definitivo. O angiossarcoma do tipo epitelióide é uma variante rara, mais comum nos tecidos moles profundos, embora raramente possa ocorrer na pele. São tumores com alto grau de malignidade, compostos por grandes células redondas, com nucléolos eosinofílicos proeminentes, nos quais a única evidência morfológica de diferenciação vascular pode ser a presença ocasional de vacúolos intracitoplasmáticos ${ }^{3}$.

No contexto de linfedema crónico, o angiossarcoma é o tumor mais frequentemente encontrado - síndrome de Stewart-Treves (SST), com comportamento agressivo, metastização e prognóstico reservado (a taxa de sobrevida aos 5 anos é inferior a 15\%)3. Pontualmente, o sarcoma de Kaposi pode surgir sobre áreas de lindedema crónico, mimetizando clinica e/ou histologicamente o SST.

\section{CASO CLÍNICO}

Doente do sexo masculino, 69 anos de idade, observado em consulta por lesão em placa eritemato-violácea que surgiu sobre área de linfedema crónico no membro superior esquerdo (MSE).

$\mathrm{Em}$ relação aos antecedentes pessoais salientava-se: (1) traumatismo vascular no MSE cerca de 40 anos antes do qual resultou linfedema; (2) sarcoma de Kaposi clássico, localizado aos membros inferiores, diagnosticado 8 anos antes, com evolução indolente, previamente tratado com doxorrubicina lipossómica e interferão- $\alpha$ (3MU sc $3 x /$ semana, posteriormente 6 UM 3x/semana), no hospital de área de residência do doente.

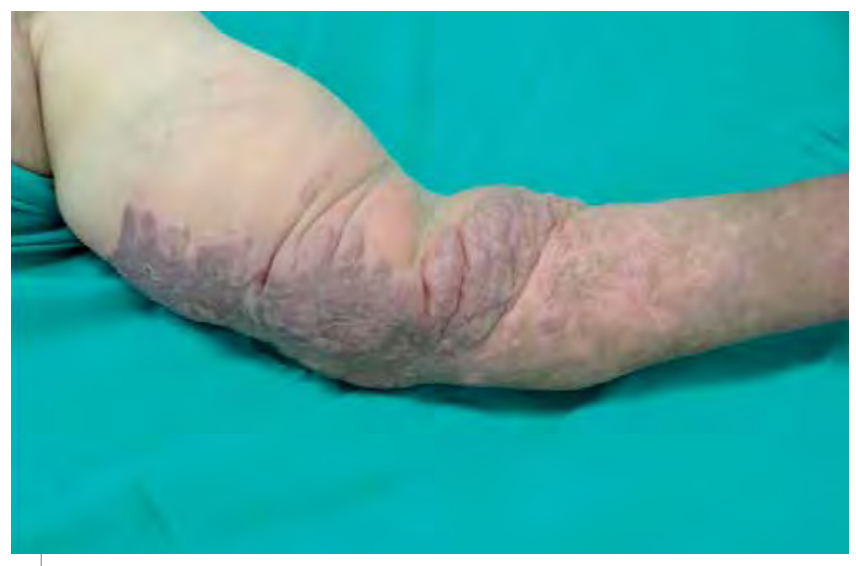

Fig 1 - Lesão em placa eritemato-violácea, bem definida, com áreas papilomatosas sobre linfedema crónico.

À observação apresentava placa eritemato-violácea, com áreas papilomatosas, elevadas, de limites bem definidos, a ocupar a região interna do MSE (Fig. 1). As lesões de SK localizadas nos membros inferiores (MI), sobretudo à esquerda, mantinham-se estáveis, com manchas eritemato-acastanhadas e áreas papilomatosas (Fig. 2a,b). O doente apresentava bom estado geral, sem outras alterações de relevo ao exame objectivo, nomeadamente sem adenopatias periféricas palpáveis. Laboratorialmente, não havia alterações significativas assinalar (HIV negativo).

Foram colocadas as hipóteses diagnósticas de angiossarcoma (síndrome de Stewart-Treves), sarcoma de Kaposi e pseudo-sarcoma de Kaposi.

A biopsia incisional realizada na lesão do MSE revelou uma proliferação tumoral envolvendo toda a espessura da derme, constituída sobretudo por células epitelioides, com alguns elementos fusiformes, e exibindo marcada atipia citológica, pleomorfismo e atividade mitótica (19 mitoses/10 CGA). Em diversas áreas observava-se formação de canais vasculares irregulares, angulosos, revestidos por células endoteliais atípicas (Fig. 3).

As imagens histológicas das lesões de SK do MI foram revistas, mostrando aspectos típicos de SK (Fig. $2 c, d)$.

Os achados histológicos observados na lesão do MSE sugeriam tratar-se de angiossarcoma. Na consulta de reavaliação, o doente referiu já ter sido efectuada uma biopsia no MSE, 8 anos antes, no hospital da sua área de residência, clarificando a evolução desta lesão, não se tratando portanto de lesão com aparecimento recente. A revisão destas lâminas mostrou aspectos de SK (proliferação de células fusiformes, 
Revista SPDV 71 (3) 2013; Vera Teixeira, José Carlos Cardoso, Miguel Pinto Gouveia, Angelina Mariano, Óscar Tellechea, Américo Figueiredo; Sarcoma de Kaposi mimetizando angiossarcoma.

\section{Caso Clínico}
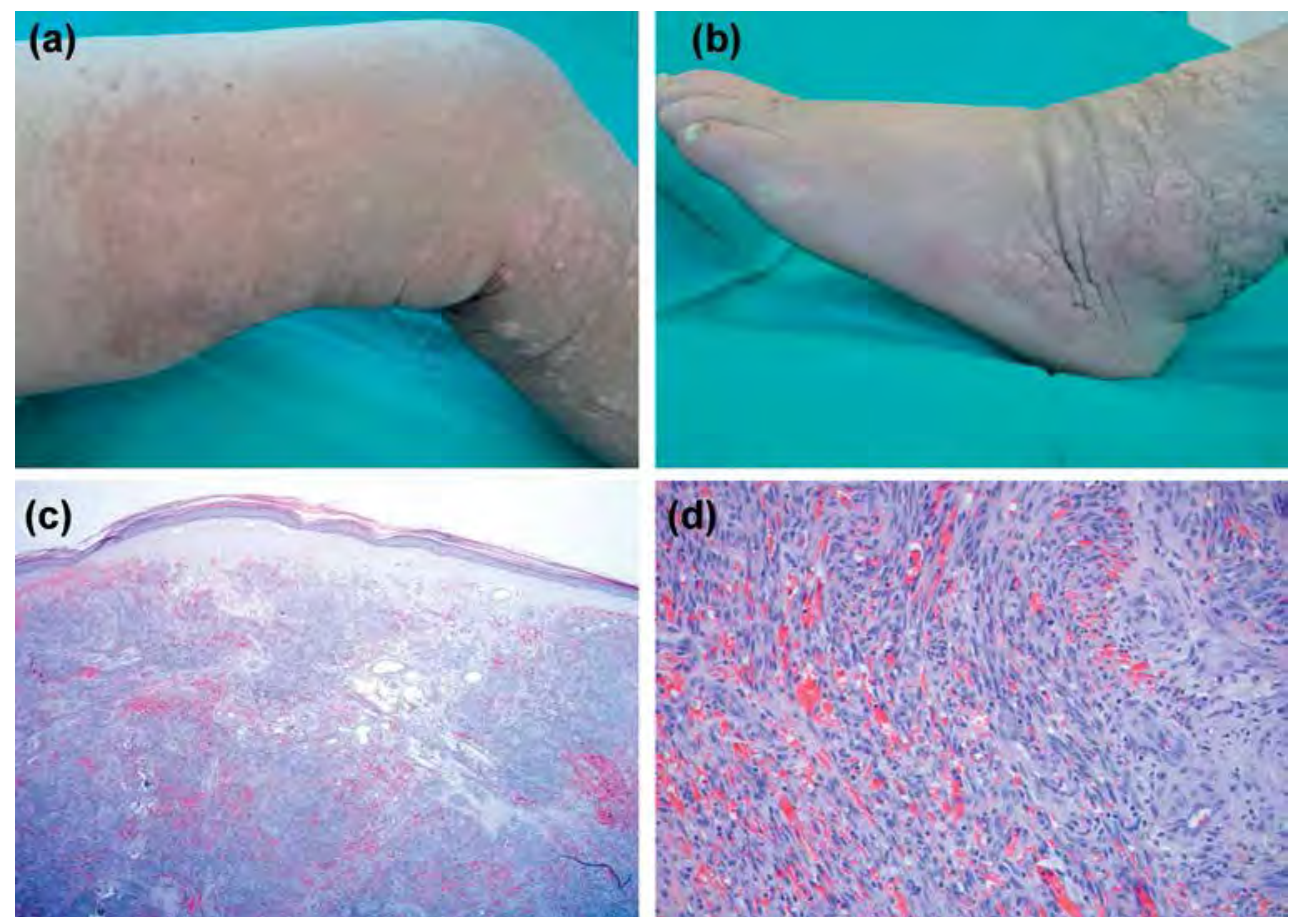

Fig. 2 - (a, b) SK clássico nos MI, com evolução indolente; (b) Aspectos típicos de SK nodular, com proliferação de células fusiformes, alongadas, formando vacúolos; (c) Notar extravasamento de glóbulos vermelhos.
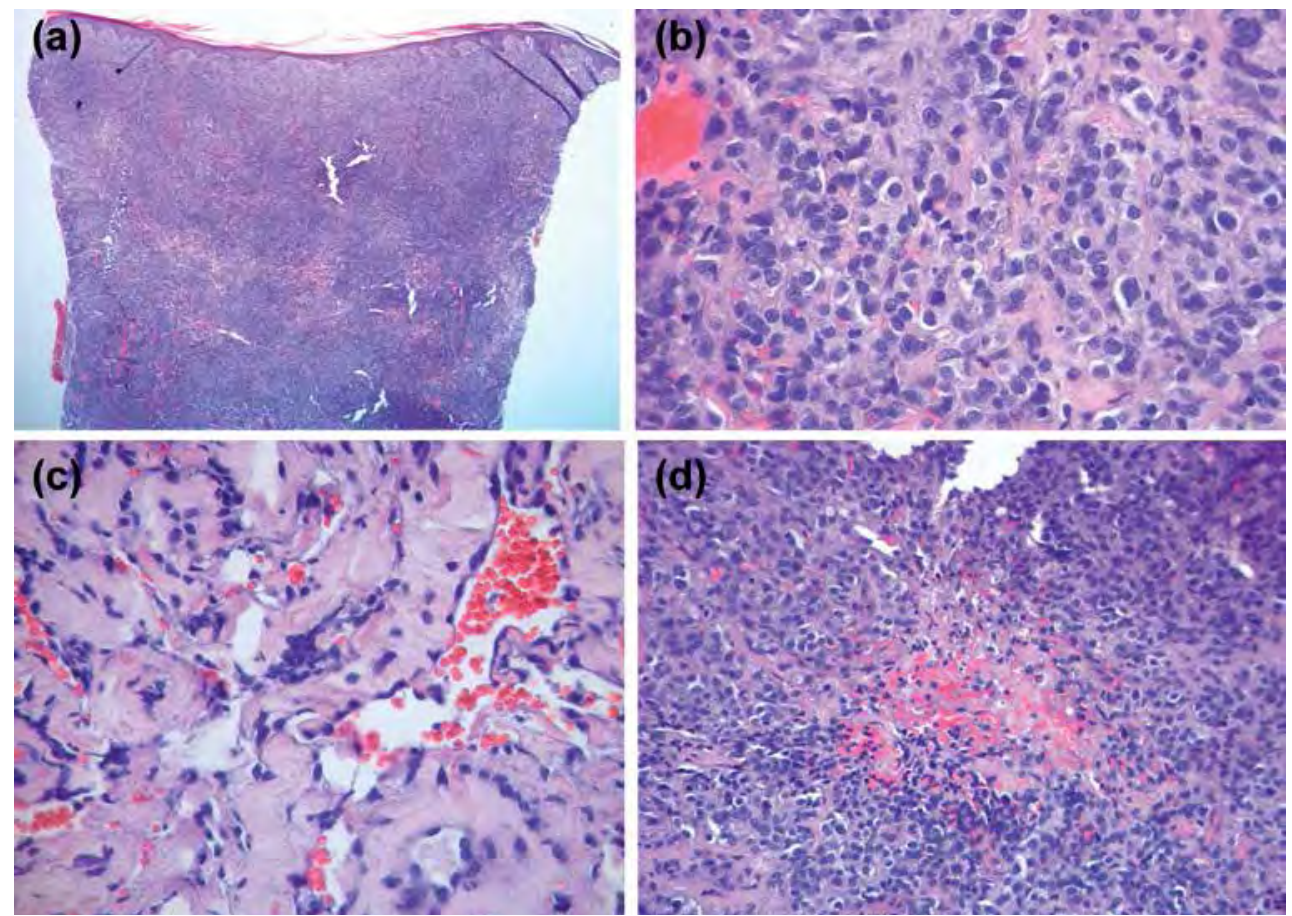

Fig. 3 - (a) Proliferação tumoral densa na derme; (b) constituída sobretudo por células epitelioides, com pleomorfismo, mitoses frequentes; (c) dissecção dos feixes de colagénio por fendas vasculares com células endoteliais atípicas; (d) foco de necrose no seio da proliferação tumoral. 


\section{Caso Clínico}
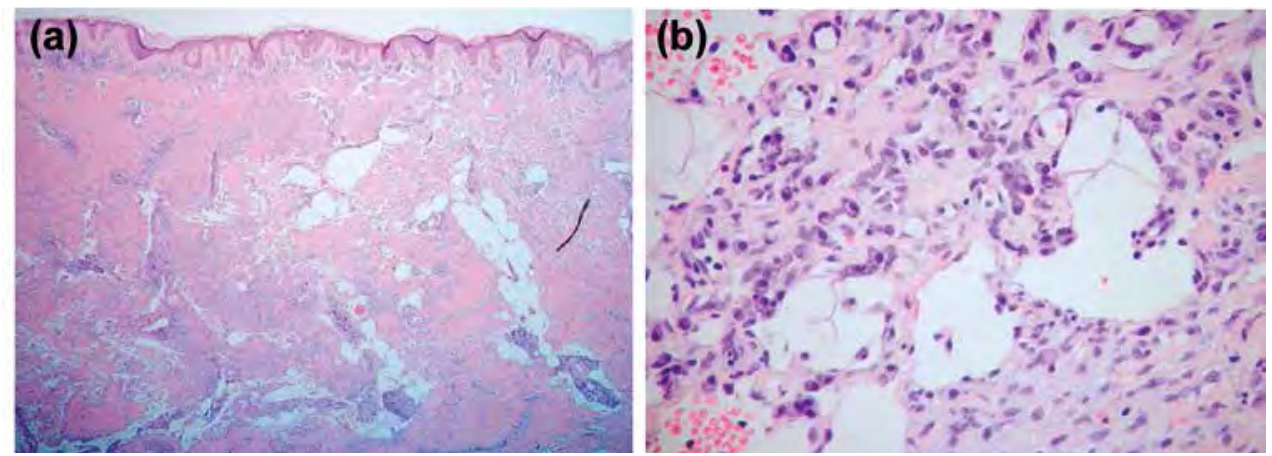

Fig 4 - Proliferação vascular com vasos dilatados, células em monocamada e células fusiformes sem atipia.

canais vasculares com células em monocamada, infiltrado plasmocitário), embora também se colocasse o diagnóstico diferencial com angiossarcoma bem diferenciado, sobretudo pela extensão em profundidade (Fig. 4).

Foram realizadas análises por polymerase chain reaction (PCR) para detecção de DNA do vírus HHV-8 na lesão do braço e na lesão de SK da perna, ambas fortemente positivas. Este dado, em conjunto com a correlação clínico-patológica levaram a reequacionar o diagnóstico da lesão do membro superior, sendo no seu conjunto compatível com sarcoma de Kaposi anaplásico.

Os exames complementares de diagnóstico realizados (TAC toraco-abdomino pélvica) não mostraram lesões secundárias. Iniciou tratamento com paclitaxel (135 mg/m² IV $3 / 3$ semanas, 6 ciclos) com notável melhoria evidenciada ao fim do 2 - ciclo de tratamento (Fig. 5).
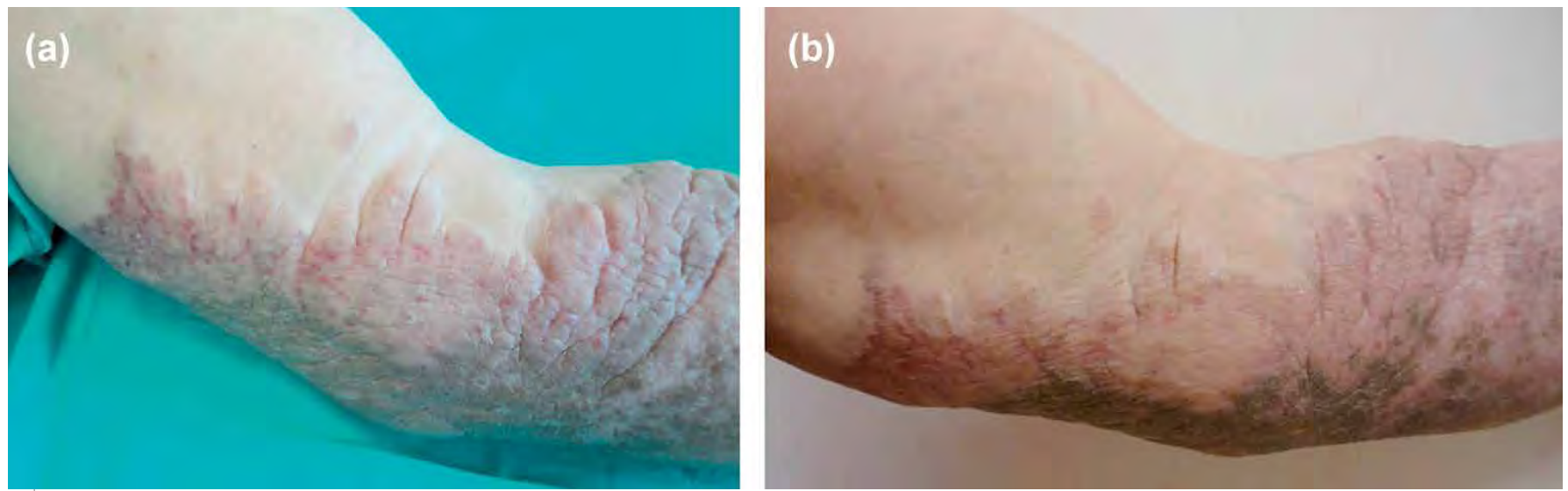

Fig 5 - (a) Resposta favorável ao paclitaxel após o $2^{\circ}$ ciclo de tratamento; (b) Aspecto clínico 2 meses após terminar o tratamento de quimioterapia. 


\section{Caso Clínico}

observa-se uma proliferação superficial na derme com pequenos vasos angulosos, delineados por células endoteliais sugestivas de origem linfática. Estes vasos delicados e irregulares dissecam o colagénio da derme e acompanham-se de um escasso infiltrado linfoplasmocitário, assim como algumas células fusiformes que expressam marcadores endoteliais.

No estadio de placa, a proliferação vascular estende-se à derme profunda e por vezes à hipoderme. As células fusiformes endoteliais também se expandem ao longo dos vasos ramificados.

No estadio nodular, as lesões são constituídas predominantemente por proliferação mais densa de células fusiformes, formando nódulos ou feixes, e separadas por fendas vasculares contendo eritrócitos. Apesar da densidade da proliferação não se observa habitualmente pleomorfismo significativo ou actividade mitótica elevada.

Nos últimos anos têm sido distinguidas novas variantes histológicas, com características particulares. Exemplos dessas variantes são: anaplásica, hiperqueratótica, linfangioma-like, bolhosa, telangiectásica, equimótica, queloidiana, granuloma piogénico-like, micronodular, intravascular, glomerulóide, pigmentado e SK com granulomas do tipo sarcóide ${ }^{8}$.

A variante anaplásica do SK é rara e pouco documentada na literatura ${ }^{9-11}$. A sua incidência exacta é desconhecida. Pode estar associada ao SK clássico, como no nosso caso, ou ao SK epidémico (associado a SIDA). Esta variante distingue-se por ter maior agressividade local e potencial metastático. ${ }^{12}$ Satta et al descreveram cinco casos de SK anaplásico, em doentes HIV negativos, com prognóstico desfavorável e curso agressivo, apesar do tratamento de quimioterapia instituído ${ }^{1}$. Estes autores colocaram como hipótese que a rápida progressão do SK anaplásico poderia ser causada pela instabilidade genética intrínseca das células malignas resultando em progressão clonal do fenótipo neoplásico.

A transformação anaplásica do SK caracteriza-se histologicamente por aumento do pleomorfismo celular, atipia citológica, elevada actividade mitótica e focos de necrose, podendo conferir ao tumor uma morfologia semelhante ao angiossarcoma, por vezes com predomínio de células epitelióides.

A maioria dos estudos mostra ausência de HHV-8 nas lesões vasculares não-SK, embora haja alguns relatos esporádicos de angiossarcoma positivos para HHV-8 detectado por PCR (até $29 \%$ dos casos numa série) ${ }^{14-}$ 16. Admite-se que estes resultados poderão resultar de contaminação por linfócitos circulantes positivos para o vírus $^{17-18}$. Em contraste, a detecção imunohistoquimica do HHV-8 parece ser mais fiável e especifica para SK ${ }^{16}$. Por motivos técnicos, no nosso caso não foi possível a realização desta análise.

Em conclusão, o SK e o angiossarcoma são neoplasias derivadas das células endoteliais, com características histológicas distintas. Contudo, as características histológicas de algumas variantes de SK possam sobrepor-se às características do angiossarcoma, tornando o seu diagnóstico um desafio.

O facto de estarem descritos na literatura casos de SK anaplásico com comportamento mais agressivo (embora em indivíduos HIV positivos) torna aconselhável um seguimento destes doentes a longo prazo.

\section{REFERÊNCIAS}

1. Mertens F, Unni K, Fletcher CDM. Pathology and genetics. Tumours of soft tissue and bone. Lyon: World Health Organization, IARC Press; 2002.

2. Bolognia JL, Jorizzo JL, Schaffer JV. Kaposi Sarcoma. In: Bologna J, Jorizzo JL, Schaffer JV, editors. Dermatology. $3^{\text {rd }}$ ed. Philadelphia: Mosby Elsevier; 2012. p.1932-5.

3. Bolognia JL, Jorizzo JL, Schaffer JV. Angiosarcoma. In: Bologna J, Jorizzo JL, Schaffer JV, editors .Dermatology. $3^{\text {rd }}$ ed. Philadelphia: Mosby Elsevier; 2012. p.1935-6.

4. Sharma A, Schwartz RA. Stewart-Treves syndrome: pathogenesis and management. J Am Acad Dermatol. 2012; 67(6):1342-8.

5. Shehan JM, Ahmed I. Angiosarcoma arising in a lymphedematous abdominal pannus with histologic features reminiscent of Kaposi's sarcoma: report of a case and review of the literature. Int J Dermatol. 2006; 45(5):499-503.

6. Salameire D, Templier I, Charles J, Pinel N, Morand P, Leccia MT, et al. An anaplastic Kaposi's sarcoma mimicking a Stewart-Treves syndrome. A case report and a review of literature. Am J Dermatopathol. 2008; 30(3):265-8.

7. Allan AE, Shoji T, Li N, Burlage A, Davis B, Bhawan J. Two cases of Kaposi's sarcoma mimicking Stewart-Treves syndrome found to be human herpesvirus-8 positive. Am J Dermatopathol. 2001; 23(5):431-6.

8. Grayson W, Pantanowitz L. Histological variants of cutaneous Kaposi sarcoma. Diagn Pathol. 2008; $25 ; 3: 31$.

9. Smith KJ, Skelton HG $3^{\text {rd }}$, James WD, Barreft $T L$, 


\section{Caso Clínico}

Anderson DW, Angritt P. Angiosarcoma arising in Kaposi's sarcoma (pleomorphic Kaposi's sarcoma) in a patient with human immunodeficiency virus disease. Armed Forces Retroviral Research Group. J Am Acad Dermatol. 1991; 24(5 Pt 1):790-2.

10. Schwartz RA, Kardashian JF, McNutt NS, Crain WR, Welch KL, Choy SH. Cutaneous angiosarcoma resembling anaplastic Kaposi's sarcoma in a homosexual man. Cancer. 1983; 15; 51 (4):721-6.

11. Chang Y, Cesarman E, Pessin MS, Lee F, Culpepper J, Knowles DM, et al. Identification of herpesvirus-like DNA sequences in AIDS-associated Kaposi's sarcoma. Science. 1994; 16; 266(5192):1865-9.

12. Satta R, Cossu S, Massarelli G, Cottoni F. Anaplastic transformation of classic Kaposi's sarcoma: clinicopathological study of five cases. Br J Dermatol. 2001; 145(5):847-9.

13. Yu Y, Demierre MF, Mahalingam M. Anaplastic Kaposi's sarcoma: an uncommon histologic phenotype with an aggressive clinical course. J Cutan Pathol. 2010; 37(10):1088-91.

14. McDonagh DP, Liu J, Gaffey MJ, Layfield LJ, Azumi
N, Traweek ST. Detection of Kaposi's sarcoma-associated herpesvirus-like DNA sequence in angiosarcoma. Am J Pathol. 1996;149(4):1363-8

15. Kárpáti $S$, Désaknai $S$, Désaknai $M$, Bíró J, Nagy K, Horváth A. Human herpesvirus type 8-positive facial angiosarcoma developing at the site of botulinum toxin injection for blepharospasm. Br J Dermatol. 2000; 143(3):660-2.

16. Remick SC, Patnaik M, Ziran NM, Liegmann KR, Dong J, Dowlati $A$, et al. Human herpesvirus-8-associated disseminated angiosarcoma in an HIV-seronegative woman: report of a case and limited case-control virologic study in vascular tumors. Am J Med. 2000; 108(8):660-4.

17. Cheuk W, Wong KO, Wong CS, Dinkel JE, Ben-Dor $D$, Chan JK. Immunostaining for human herpesvirus 8 latent nuclear antigen- 1 helps distinguish Kaposi sarcoma from its mimickers. Am J Clin Pathol. 2004; $121(3): 335-42$.

18. Schmid H, Zietz C. Human herpesvirus 8 and angiosarcoma: analysis of 40 cases and review of the literature. Pathology. 2005; 37(4):284-7. 